\title{
A Humanistic Model for the Higher Education Excellence: Embedding Confucianism and Islamic Principles
}

\author{
Yu Sing Ong \\ Dr, Professor, HELP University, Malaysia
}

\begin{abstract}
Both Confucianism and Islam offer a humanistic approach towards the concept of leadership, emphasizing ethical practices such as integrity, trust, moral characters, and justice. They are perceived as a means of providing moral values and countering the negativity associated with modernity. They provide the cultural and moral capital to university leaders, which affect leadership practices and organizational cultures of higher education institutions in Asia. Leaders are expected to maintain a high level of integrity and responsibility. University leaders and administrators are often guided by their respect for cultural traditions and this study helps to provide an understanding of higher education leadership in China, Singapore and Malaysia. This article offers a comprehensive view of excellence in higher education ranging from policies to practices of university leaders and academics, based on previous and current works of the author. Subsequently, the findings provide the basis for developing a humanistic multidimensional model for higher education excellence, embedding the principles of Confucianism and Islam. The rigor and richness of the findings will contribute to the development of higher education leadership in Asia.
\end{abstract}

Keywords: Confucianism, Islam, higher education excellence.

JEL Classification: I23, Z12.

(C) The Author, 2018. This article is published with open access at Sumy State University.

\section{Introduction}

The cultures of the East and West are different. In the East, education is seen as the route to social status. The education landscape in China, Singapore and Malaysia are influenced by the convergence of Western and Eastern value systems: Confucianism, Islam, communism, and Western management principles. While there are apparent dichotomies between Eastern and Western philosophies, university leaders could adapt the competitive dynamics of Western management science to fuse with the cooperative relationships associated with Eastern thinking. Western paradigms do not always connect with the realities of Eastern people and can have a distorting effect. With the rise of nations in the East, especially China, and to a lesser extent the Asian Tigers, scholars should pay more attention to the specific conceptual and cultural paradigms and not impinge Western points of views without profound knowledge of the epistemological implications of such paradigms.

Western researchers' bias towards Eastern researchers may be due to their failure or lack of experience in making the connections with Asian social systems (Yu, 2016). To appreciate another set of cultural dynamics, researchers need to be aware of their own beliefs, assumptions and expectations, and not ignore the differences, which exist in other cultures. Western researchers need to reinterpret, remodify, and redefine the concepts such as knowledge, honor, truth and ethics in order to understand Eastern values and beliefs, which are culturally embedded. Limiting the diversity of theory, which can generate knowledge, will only prevent Western theorists from understanding the East and from gaining access to the rich knowledge, which could be offered. Ethnocentrism is harmful to those interested in the pursuit of knowledge about other cultures. Bizumic et al. (2009) defined ethnocentrism as an attitudinal construct that involves a strong sense of ethnic group selfcenteredness and self-importance.

Globalization calls for the major transformation of higher education institutions. There is a gradual shift in organizational paradigm from that of traditional centralized control and bureaucratic nature to one which promotes organizational learning. People in learning organizations aspire for more autonomy and are intrinsically motivated to achieve desired results. Developing, motivating, and retaining people to be committed to the organization's vision, goals and values are major challenges faced by university leaders. The humanistic approach of prioritizing the human existence, duties and potentials is found in both Confucianism and Islam (Tan and Ibrahim, 2017). The author aims to share his perspective on creating excellence in private 
higher education institutions in China, Singapore and Malaysia taking into consideration the strong philosophical influences of Confucianism and Islam on the management practices of university leaders.

\subsection{Problem Statement}

The influence of Confucianism and Islam on university leadership practices have not been researched widely. While much work has focused on leadership from a business perspective, many educationists have not sought a similar approach to applying these philosophical and religious concepts in their leadership practices within their institutions. This study responds to the need for a more scientific approach to leadership development within the context of higher education institutions in Singapore, Malaysia and China. Hence, this study responds to the call and expands the scholarships on the application of Confucianism and Islam to enhance the leadership practices of university leaders. Unlike Western concept of self-contained individualism which sets a clear-cut boundary between one's self and others, leaders in Confucian and Islam-influenced societies are expected to fulfill role obligations in relationships, particularly towards society or ummah (larger community).

\subsection{Significance of the Study}

This study contribution to knowledge had been made through the development of numerous conceptual models of education leadership, management and quality assurance from a Confucian and Islamic perspective. It had articulated key elements of Eastern philosophies and religions and gave deep insights of how they guided leaders in managing and growing their institutions. In doing so, it had contributed to the theories, discourses and practices on higher education leadership which are predominantly embedded in Western philosophies and values. The study provided the theoretical logics and rationales explaining university leaders' behaviors and their motivations in China, Singapore and Malaysia. Theoretical corroborations and empirical findings of case studies in this paper were discussed. The various methodologies in this paper had provided a better understanding of complex intercultural processes in the field of educational leadership than previous studies which largely focused on cross-cultural comparisons of leadership differences between the West and the East. Existing literature on higher education mostly focuses on Western constructs, which may have limitations when applied to Eastern contexts. New approaches to leading and managing higher education institutions need to move beyond ethnocentric theories as Western thinking may not necessarily work well in another cultural setting. The Eastern concept of leadership emphasizes more on relationships and engagement with others in concerted actions to achieve common goals. The notion of relational identity is closely related to collective identity, wherein a person's identity is defined by his or her membership in the reference group to which he or she belongs.

This paper had covered a broad spectrum of issues relating to educational policies, quality assurances, teamwork, talent development, power and conflict, competition for resources, institutional culture and organizational sustainability. It included an examination of the concept of education in Confucian and Muslim contexts. The researcher introduced a humanistic multidimensional model of self-directed inner reflection, basing on the Confucian concept of jen (best virtues) and the Islamic principle of ihsan (attaining perfection) to achieve excellence in a higher educational institution context. According to Confucian ethics, university leaders are endowed with a mission to promote Confucian teachings not only within their family but also in the whole community. The study also suggested potential lessons to be considered for future scenarios faced by higher education institutions. In addition to discussing practical challenges that need to be overcome, the researcher argued that there was a need for institutions to constantly review their mission, aims, and objectives in light of the wider economic, socio-cultural and religious development of a society. Therefore, this study provided an opportunity for future researchers to debate with the existing literature on the influence of Confucianism and Islam on higher education leadership practices in China, Singapore and Malaysia.

\subsection{Research Questions and Aims}

The research question underpinning this research is:

1) What are the lessons university leaders could potentially learn from Confucianism and Islam in order to develop excellence in their institutions? 


\subsection{Conceptual Humanistic Multi-Dimensional Model on Education Excellence}

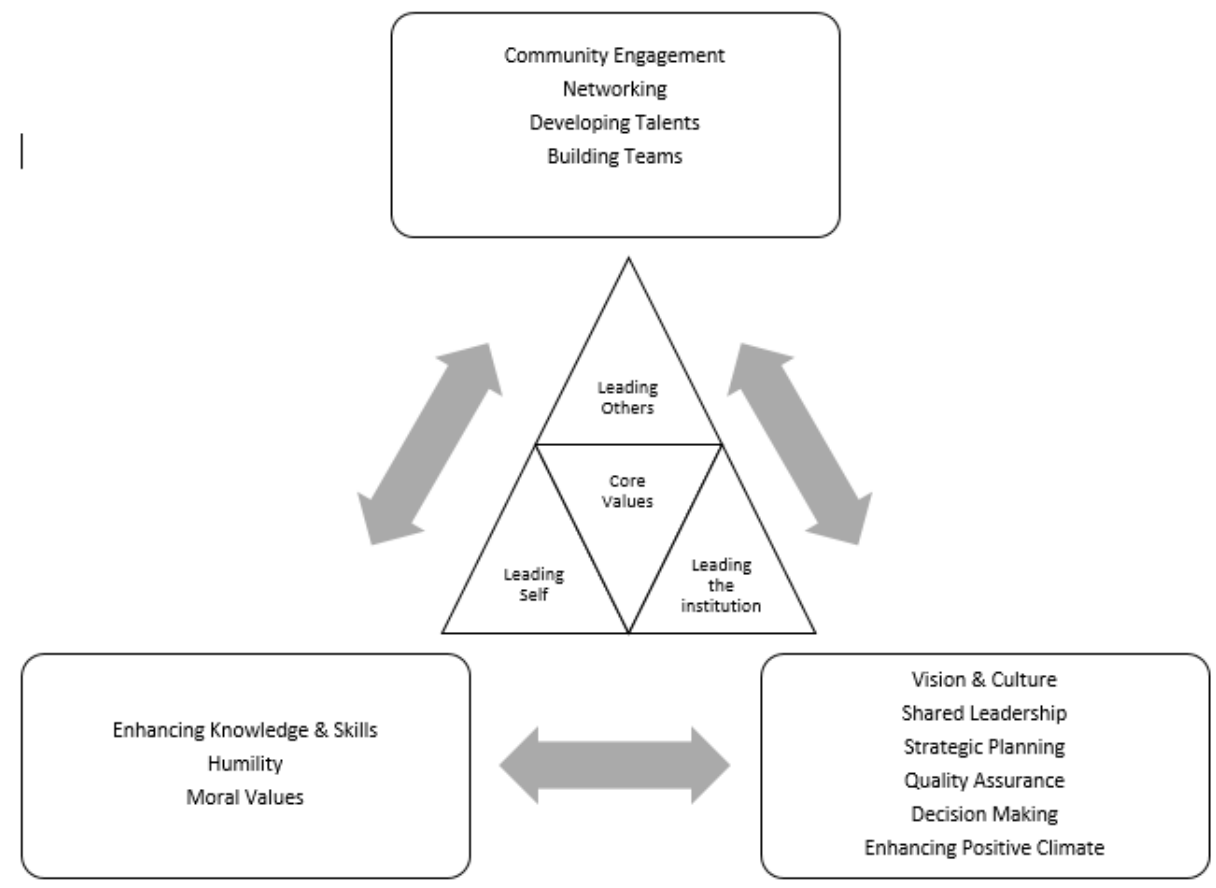

Figure 1. Proposed Humanistic Model on Educational Excellence

The proposed conceptual Humanistic Multi-Dimensional Model on Educational Excellence focuses on three main leadership roles to guide the higher education institution: Leading Others, Leading the Institution, and Leading Self. At the core of the framework are a set of institutional and personal values. This model addresses the significance of reflection on the higher education leaders' practices in managing their institutions. It serves as a guide to higher education administrators regardless of the size and sophistication of the institutions.

\section{Methodology}

A variety of research methods were used for this paper as the researcher covered a broad spectrum of topics. Both theoretical research as well as empirical research methods were presented in the different sections. Theoretical research enabled the researcher to explore and discuss a research object based on abstract theoretical structures and philosophical concepts. Empirical research enabled one to explore an object on the basis of observations on the object studied.

Crotty (1998) suggested the use of both ontology and epistemology in designing the research approach. Ontology is concerned with the being or the nature of existence and how we view our reality. Pring (2000) noted the existence of polarity among educational researchers. As one end, there is the objectivism which views that one reality exists. Grix (2002) postulated that social phenomena and its meaning existed in reality external to social actors concerned with their existence. Alternatively, objectivism is an ontological position that asserts that social phenomena and their meanings have an existence that is independent of social actors.

At the other end, there is subjectivism, with the view that there are multiple realities that exist and reality is based on one's perception of it (Pring, 2000). Subjectivism (also known as constructionism or interpretivism) perceives that social phenomena are created from the perceptions and consequent actions of those social actors concerned with their existence.

I believe that reality is a product of an individual social, cultural and educational experiences. How one perceives and interprets it depends on his past experiences. In summary, the constructivist ontology with an interpretivist epistemology was chosen for this research.

\section{Philosophical and Religious Approach to Educational Leadership and Management}

\subsection{Confucianism Concept of Education}

Confucius teachings are delivered in the Analects, which is a collection of sayings and ideas attributed to the Chinese philosopher and his contemporaries. They form the foundation of Chinese perspective on education, 
an ideal person, and an ideal society. Confucius expected students to put in their best effort and he was willing to teach anyone who wanted to learn regardless of his ability. He encouraged them to absorb the knowledge taught to them, assured that they learnt the essentials, and not merely repeating the words without truly understanding the knowledge contained in those words. He often encouraged students to reflect on and debate about real life social issues as he believed linking textual knowledge with practice would enhance students learning. He believed that the inner goodness of man is only made possible through good education.

The focus of learning was on reforming the individual behavior. He often exhorted his learners with short homilies about virtuous behavior. He believed that through virtuous behavior, individual success and society harmony could be achieved. Teachers are expected to hold a high degree of virtuous behavior as they exert a positive influence on others. The basic Confucian virtues include benevolence, righteousness, courtesy, wisdom and trust. Learning and reflecting are associated with the development of one's moral values. Reflection is a skill, which requires teachers to examine their knowledge and experiences in teaching subject matters to their learners. It is one of the key factors in linking theory with practice. Lifelong learning was advocated by Confucius not only for employability but also for personal development. This has become increasingly important with changes in demography and skills set required for modern day employment. More universities are realizing the need to offer lifelong learning education programmes to mid-career professionals or older students returning to further their education. Virtues such as benevolence, humility and integrity can only be achieved through continuous self-improvement (Sun, 2008).

To achieve an education-oriented society, Confucius maintained that education should be made available to all, irrespective of social class. With good knowledge and education, one is able to achieve self-cultivation first. Only when a character is cultivated can harmony in family exists. Only when families are harmonized, can a state be regulated orderly. To Confucius, the role of education is important to produce good and capable men to serve in government. Families are component units of society, which supported the state through obedience and producing future officials. The maintenance of social order calls for a harmonious relationship between the society and the government (Figure 2). The contribution of higher learning institutions is embodied in keeping the institutions in harmony with the state.

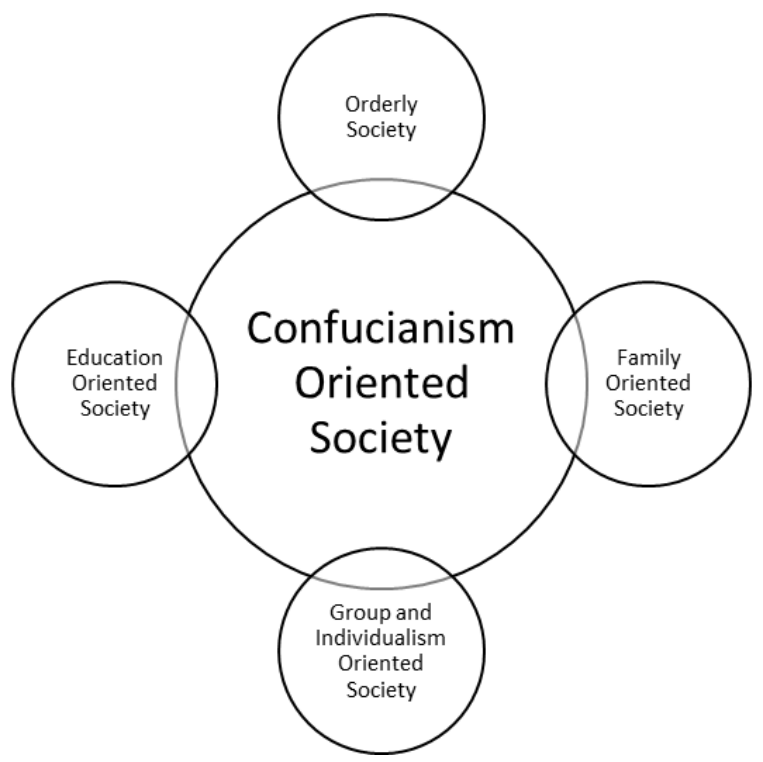

Figure 2. Confucianism-oriented Society

Confucius expected learners to obey authority. In most Chinese societies, Confucianism still plays an important role in constructing the modern secular ideology, which accommodates diversity yet maintaining a harmonious social-political environment ( $\mathrm{Xu}$ and Wang, 2018). The Chinese culture views overt questioning of authoritative knowledge as threatening the social harmony by disrupting the power distance between teachers and learners. Leaders need to have high standards of ethics and be knowledgeable. A knowledgeable person is a junzi (enlightened person) who maintains the right virtues. Knowledge was associated with high social class, high moral character and leadership. In ancient China, scholars who passed the national exam are often awarded an official position with the government. Education achievement is the route to success in society. Confucian-influenced societies like China, Singapore, and Malaysia are increasingly placing more emphasis on evaluating the performance of leaders to ensure that they are professionally competent and morally upright. 
The sharing of ideas and exchange of knowledge among the broader community is more important than the physical environment. This forms the fundamental basis of the relationship between teachers and learners. As role models, teachers must pay attention to their personal relationships with learners, which is guided by the principle of ren (benevolence). Chinese tend to view education as a means to an end. These contrasts with Western philosophy, which sees learning, should be its own end. Some researchers view Confucian and Western approach to learning as dichotomous with comparisons such as surface versus deep, and dependent versus independent (Ryan and Louie, 2007). This is an oversimplification, ignoring the developments of globalization and the influence of Western philosophies on Eastern teachings and vice versa.

The teachings and value systems of Confucianism is the key to China's challenge to Western hegemonism in higher education. Confucianism emphasizes an orderly society and stresses loyalty, duty and public service ( $\mathrm{Yu}, 2017)$. The role of higher education in projecting China's soft power is receiving a lot of attention as the country raises its economic and political clout. Values espoused by Confucius such as humility, trust, honesty, respect and openness have impacted Chinese society and gained the attention of Westerners. These values are reflected in the behaviors of students as well as staff and leaders of higher education institutions. The Confucian moral philosophy, primarily the Analects, provide a guide for leaders to regulate their own behavior and to maintain a high moral and ethical standard. Self-regulation is a continuous process towards selfcultivation and refinement of one's character.

\subsection{Islam Concept of Education}

The Islamic concept of education emphasizes on the acquisition of knowledge. Acquiring knowledge is obligatory to every Muslim. Education is recognized as one of the building blocks for the sustainable development of the community. Through education, an individual strives to adopt a balanced growth of his total personality comprising the heart, spirit and intellect. He is encouraged to strive to become insan kamil (perfect man) and live his life according to the teachings of Quran. The Quran stresses inquiry and reflection while suggesting shura (consultation) and ijtihad (rational consensus), at the same time providing room for ikhtilaf (debate). Education in Islam aims not only at the moral edification of the individual but also his service to the society at large. Education encompasses tarbiyah (nurturing), talim (learning) and tadib (goodness). The educational leader is a muallam (teacher) and a guide to taqwa (right path). He or she is a role model embodying the good moral qualities for others to follow.

Halstead (2004) asserted that there is a contrast between the liberal and Islamic concept of education. He noted that liberalism regards rationality and intellectual freedom as its main pillar. On the other hand, the Islamic view on education does not give legitimacy to autonomy and freedom of reason. The difference in opinion between a Western scholar and an Islamic scholar on the concept of education is based on the specific nature of Islam where Allah is the center of all things.

The Quran and hadiths are filled with references on knowledge, learning and reasoning. Learning and deepening one's knowledge is an act of worship. Learning and seeking knowledge is not confined to textbooks. Muslims have to keep their minds open to receive all kinds of rewarding experience. The Islamic concept of ilm (knowledge) covers a much broader context than the Western definition. It covers theory, actions, and education. Education, including the educational process, is defined as the recognition and acknowledgement, instilled into a man in the order of creation, such that it leads to the acknowledgement of the proper place of Allah in the order of being and existence. There are three types of ilm: information, natural laws, and knowledge by conjecture.

"So high (above all) is Allah, the Sovereign, the Truth. And, (O Muhammad), do not hasten with (recitation of) the Qur'an before its revelation is completed to you, and say, "My Lord, increase me in knowledge" (Al-Quran, 20: 114). 


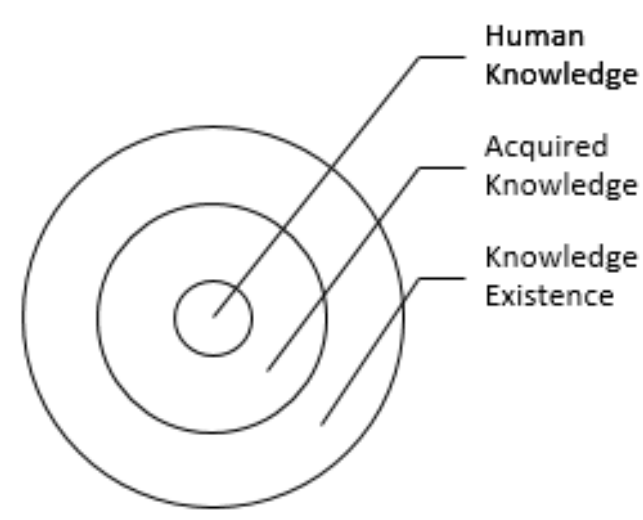

Figure 3. Islamic Knowledge Management

\section{Creating the Cultural Uniqueness of the Institution}

This section explores the notion that management practices in the Orient are slightly different from the West. The general awareness of emerging Asian leaders has created an interest in exploring the frames of references from an Asian perspective.

Businesses in the Orient emphasize more on building relations or guanxi as the formula for a long lasting relationship. Foreign universities need to have an understanding of issues relating to language, behavior, rituals, labor relations, workforce attitudes, and consumer preferences. If managed properly, a multicultural work environment will promote workplace learning as it facilitates the exchange of new ideas between colleagues from different backgrounds.

Hall (1976) introduced the concept of high and low context communication cultures. In high context cultures, communication is largely implicit and that relationships are more important than actual words spoken. In low context cultures, communication is largely explicit and by words. China and Muslim countries exhibit a high context culture while Western countries generally display low context settings.

Western research methodologies may not fully address research studies on Eastern cultures. Its differences with Chinese philosophies were highlighted with the concept of dao (Way) and Confucianism. More than just an epistemological discussion, the author argues that Western researchers bias towards Asian researchers may be due to their failure or lack of experience in making the connections with Asian social systems (Yu, 2016).

Western researchers have often criticized that Confucianism fails to provide the rights of individuals that may have a conflict with the community. They argued that Eastern cultures suppress dissenters who attempt to highlight power abuses by authorities. In a broader sense, this seems contradictory as some Western researchers seek to impose their beliefs on Asian researchers in peer review articles. They seek to ignore or downplay alternative views and opinions of Asian researchers indicating faults in their research methodologies. These incidents highlighted the myopic views of some Western researchers who do not fully understand the background of the Asian culture. The Analects of Confucius maintained that "in teachings, there should be no distinction of classes". Similarly, there should be no distinction in terms of superiority or inferiority as far as knowledge, culture, experiences and beliefs are concerned. Each culture emphasizes different values and there should be no judgement of superiority or inferiority. On one hand, some Western researchers advocate the rights of dissenters to voice their views, but on the other hand, they fail to acknowledge that there are differences in their philosophical views with Asian researchers (Yu, 2016).

Comparative philosophy focuses on the understanding of historical developments, similarities and dissimilarities between different cultures or ethnic groups. Different social systems will adopt different approaches and methodologies to the subject of study. Rather than viewing Asian researchers from a Western perspective, Western and Eastern researchers should learn from each other and jointly collaborate on research studies or topics of philosophical significance. This conclusion is anecdotal rather than empirical, as any comparative research on this topic will likely be mired with biases of the researchers. The cultural complexities across borders make it an even more challenging tasks to conduct education research objectively for the research design and methodologies in themselves will display elements of biases due to the predilections, beliefs and experiences of the researchers. 
An understanding of cross-cultural management issues is essential for foreign universities to penetrate the host Asian country. This understanding is even more important if the foreign university chooses to establish an operation in the host country as it may require different organizational structures and human resource management policies. Managers need to be acquainted with specific cultural issues so that they can make better decisions and avoid unnecessary conflicts and losses.

\section{Developing the Key Strategies}

$\mathrm{Yu}$ (2012) conducted a study on the complexities of multiple paradigms and overlapping influences in university leadership. The perceptions of the key issues and challenges facing higher education leaders in their work are discussed. The study found that much challenges centered around the need for strategic leadership, flexibility, autonomy, managing and motivating staff, responding to competing tensions and maintaining institutional quality. The author also came up with some proposals for university leaders to deal with the challenges they face.

A qualitative study was conducted to investigate the perceptions of mid to senior level managers of a private Malaysia university on what were they see as the main issues and challenges facing them today. A total of fifteen managers, ranging from Head of Schools, departmental heads and faculty administrators participated in the interviews. Open-ended questions were posed as they provided the opportunity for the participants to express their views. This methodology, where interviews were normally held in informal settings where participants felt comfortable to provide their views is the most effective method in qualitative research (Silverman 2000).

Each participant was asked the same set of questions with the flexibility to explore issues that may surface during the interview (Merriam, 1998). The advantage of this type of interview is that they reduce interviewer bias during the interview and facilitation of organization and analysis of data (Fraenkel \& Wallen, 2003). The interview protocols consisted of ten semi-structured, open-ended questions in the endeavor to gain insights into the participants' perceptions of leadership practices.

The study noted that participants considered three main drivers of motivation. The first was the ability to make a difference in other people's lives. This included imparting their knowledge to students. The self-efficacy theory of Bandura (1997) is centrally relevant to their beliefs in their capacity to successfully carried out their given tasks and the consequent impact this belief has on their motivation.

The second area was their working environment whereby they felt that their contribution would be appreciated. This included opportunities for career advancement as well as personal growth. Rowe \& Rowe (1999) found that teacher professional development has the potential for enhancing the educational outcomes of students and assisting teachers to operate more effectively in the classroom.

The remaining area was related to salary and benefits. While they were altruistic in nature, a low compensation package would lower their motivation and even prompt them to seek alternative employment elsewhere. All participants regarded salary level and welfare conditions as factors affecting their job satisfaction. However, they were also intertwined with other factors such as university leadership, professional development and a sense of achievement through teaching.

Maslow's (1954) needs theory raised the question as to whether people's needs would be met by choosing careers, which related to job satisfaction. The absence of three higher-order needs (self-esteem, autonomy, and self-actualization) was shown to be a major contributor to low teacher satisfaction (Carver \& Sergiovanni, 1971; Frances \& Lebras, 1982; Sweeney, 1981; Trusty \& Sergiovanni, 1966).

Bandura's (1997) self-efficacy theory relates to whether people believe they can be successful in their chosen careers and the number of career alternatives that they may consider. He suggested that self-efficacy influences performance, behavioral choices, and persistence and is related to career choice in a number of ways. Selfefficacy complements skill sets in individuals seeking careers and may facilitate career attainment for those seeking careers in areas that they are competent in.

Research has shown that a positive school culture was associated with increased student motivation and achievement, improved teacher collaboration, and improved attitudes among teachers toward their jobs (Sashkin \& Wahlberg,1993; Ogawa \& Bossert, 1995). Teachers are transformational leaders and they may also influence students' performance if they are motivated themselves. Ryan and Deci (2017) noted that selfdetermination is driven by innate individual needs to seek control of outcomes, to connect with others and to be a causal agent of one's own life, and rooted in human motivation. 
The assessment and evaluation of the effectiveness of a university leader is more than just his knowledge in finance, strategic planning or curriculum development. In the corporate environment, an effective leader is measured by his performance in bringing the company to profitability and maximizing the return on investment (ROI). In an educational setting, the emphasis on the development of dispositions to motivate the application of knowledge and skills, and technical expertise is of equal importance. Dispositions are defined by Perkins (1995) as proclivities that motivate and determine the direction of behavior.

The competency of the university President to lead is an area of research, which has generated much interest. $\mathrm{Lu}$ (2016) noted that academic leadership competency is the leading cohesive force within the university setting. The competency of the leader also affected many soft factors such as motivation of faculty members (Guo and Xiong, 2010) and played an important role in shaping the work environment of the faculty (Fu, 2013).

The work of Goleman (1998) in the area of emotional intelligence focused on assessment and evaluation of leader behaviors not related to technical skills in the areas of finance, curriculum development, or strategic planning. Emotional intelligence is defined as the awareness of emotions and using emotions to make good decisions. Emotional intelligence involves empathy, managing emotions in relations, and persuading others (O'Neil, 1996). Salopek (1998) stated that competencies associated with emotional intelligence are more important in effective job performance than our ability and expertise. To be a successful leader, the individual needs to possess a high level of emotional competencies. From the study, the participants did not question the technical competencies and cognitive abilities of the university leaders. However, they remained unconvinced about the leaders' emotional competencies. The lack of trust in subordinates, the inability to keep emotions under control, the lack of empathy, the failure to proactively understand and meet other's needs and the difficulty to inspire others were some issues highlighted during the interviews. University leaders should find strategies to work through these situations if they are to earn the respect and trust of their colleagues.

The study revealed the need for university leaders to acknowledge the human dimension in the process of achieving their corporate goals. They need to be able to engage staff to embrace strategic change rather than focusing on the structure itself $(\mathrm{Yu}, 2012)$. Leaders need to get individuals involved in accomplishing specific tasks. They need to be able to enter into an honest dialogue with the team members and be willing to hear different opinions on all issues. The findings revealed that it is essential for university leaders to work to develop the positive people skills and necessary communication skills to maintain the respect and treatment that members of the organization deserve.

Both Confucianism and Islam offer important lessons to university leaders in engaging and motivating employees. Confucius advocated ruling by moral example and doing what is right instead of what is to one's advantage.

In the Analects of Confucius, Book 12, Ji Kang Zi asked Confucius about government,

"Suppose I were to kill the unjust, in order to advance the just. Would that be all right?"

Confucius replied: "In doing government, what is the need of killing? If you desire good, the people will be good. The nature of the noble man is like the wind, the nature of the inferior man is like the grass. When the wind blows over the grass, it always bends".

The concept of servant leadership has always been part of Islam. Muslim leaders need to have the niyyah (right intention) to help those around him to succeed. Servant-leaders foster collaboration by serving the community. They place themselves in the shoes of their followers and doing what they asked their followers to do. They focus primarily on the growth and well-being of the followers and communities to which they belong.

The Prophet (pbuh) was an excellent role model who joined others to build the mosque in Madinah and dug the ditch prior to the battle of Ahzab.

"So by mercy from Allah, (O Muhammad), you were lenient with them. And if you had been rude (in speech) and harsh in heart, they would have disbanded from about you. So pardon them and ask forgiveness for them and consult them in the matter. And when you have decided, then rely upon Allah. Indeed, Allah loves those who rely (upon Him)" (Al-Quran, 3: 159).

Servant leadership is about the leader who is a servant first. The teachings of Quran and the lifestyle of the Prophet (pbuh) is taken as guidance for believers. The Prophet (pbuh) focused on people and their needs as a priority. He had demonstrated genuine concern for the well-being of his followers and has shown mercy, justice and kindness as part of his leadership skills. 
Servant leaders are committed to building the community. This was shown by the Prophet (pbuh) when he called for the establishment of a community upon his arrival in Medina. The Prophet (pbuh) also recognized the importance of education and knowledge as the necessary ingredients for building community and sustaining the growth of the community.

It is important for servant leaders to listen attentively to their followers. They have to display empathy and be competent in healing their emotional setbacks. The Prophet (pbuh) had demonstrated many examples of showing mercy and healing people.

"There has certainly come to you a Messenger from among yourselves. Grievous to him is what you suffer; (he is) concerned over you and to the believers is kind and merciful" (Al-Quran, 9: 128).

The benefits of servant leadership of an organization include higher employee job satisfaction, teamwork, lower turnover, better customer retention and improved profitability (Figure 4).

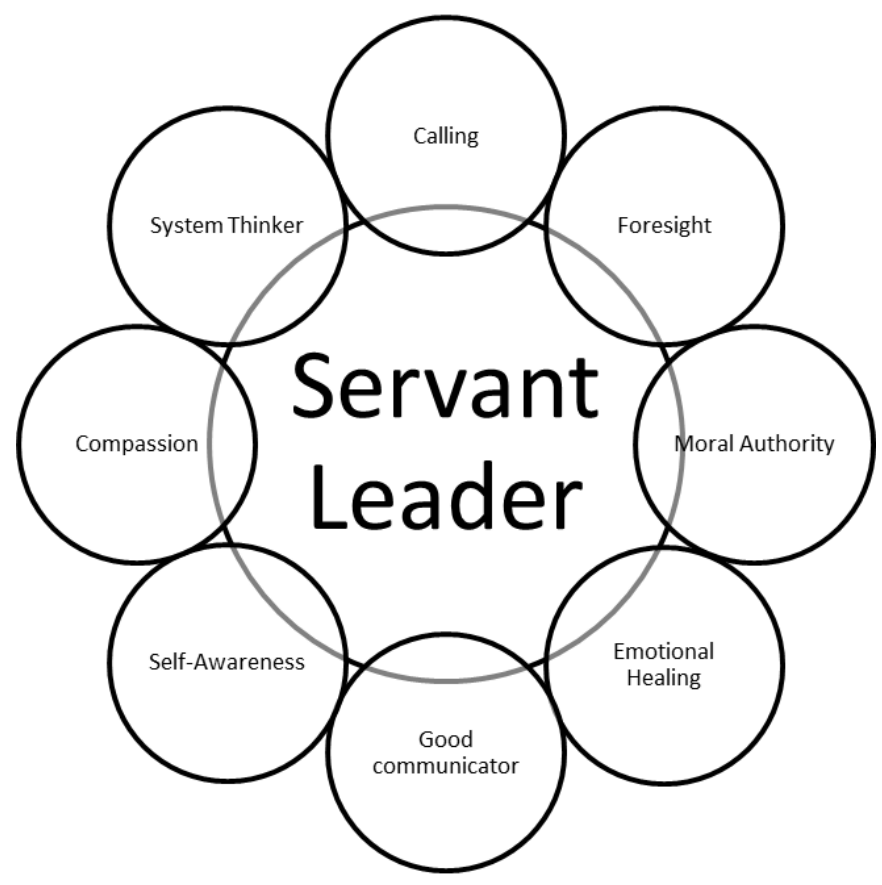

Figure 4. Servant Leadership

The participants of the study indicated that continuous improvement could only be achieved in an environment where leaders are open to hearing their opinions. The organizational learning experience will be restricted unless there is a way of sharing the insights gained. Universities need to pay close attention to the tenets of leadership and selecting candidates based on their beliefs, skills and knowledge regarding the process of improving the educational institution. The quality enhancement transformation process requires commitment from top management as well as attitudinal changes from faculty and staff.

\section{Reculturing the University}

This section explores the key issues and challenges facing private university leaders today. Universities are reculturing their operational processes, academic content and interactions with stakeholders. Much challenges centered around the need for university leaders to reculture the institutions and the redesigning of the teaching profession. Yu (2016) recommended a framework for university leaders to deal with the challenges they face. Only through reculturing, universities are able to maintain the sustainability of its workforce and student population. The article has both theoretical and practical significance for university leaders to follow.

The five components in our proposed detailed framework for the sustainability of private universities are not independent. They are highly intertwined and tend to reinforce each other. Universities need clear and strong cultures to foster professional learning $(\mathrm{Yu}, 2016)$. When universities have strong positive cultures, staff and student learning will thrive. Conversely, negative cultures can impair staff development. Teachers and staff professional development and quality curriculum are the keys to successful reculturing of universities. University leaders must develop cooperative relationships with employees to build a strong learning community. With strong cultures of trust, openness and collaboration that support both students and staff 
learning, private universities will be able to sustain high performance and remain competitive in the long run. The leader should adopt new approaches to solving problems in light of the rapid development caused by globalisation. The creation of an innovative culture requires leaders to have new skills to engage employees (Barsh et al., 2007). These include coaching and facilitating skills. Mohr (2010) noted that leaders should possess the skills to envision the future and generating insights that are not constrained by current policies.

The university is an ecosystem made up of interrelated and interdependent parts. As a self-learning and selfadapting system, it is essential that it adjusts itself with the environment. Drawing on ecological systems theory to characterize reciprocal and person-environment interactions, we could categorize the university ecosystem into five layers: individual, interpersonal (peers, social networks), community (relationships between organizations), organizational (organizational and social institutions) and policies.

These five layers align closely with the hierarchical systems in many Confucian societies. The family unit is the center of an individual life's and greatly affects one's educational achievement. Confucius advocated five basic relationships for humans: father and son, husband-wife, elder-younger, friend-friend, and emperorsubject. In the higher education environment, the virtues of family hierarchy and filial piety portray the relationship between leader (parent) and subordinates (child). Filial piety is reflected in the subordinates respect and obedience on authority. Confucianism promotes social harmony in human relationships. To achieve harmony within the context of the university environment, it often relies on considering the leaders' authority and the role and responsibility of every individual. Chinese culture is quite diverse due to the large geographical region in East Asia. It consists of many ethnic groups, each having its own customs and traditions. Confucius saw diversity on many levels as beneficial to cultivating social and universal harmony. He understood a ruler's need for ministers with varied opinions to offer counsel to reach the best decision, to a chef's need to have diverse ingredients to prepare a good meal. In the Zhou Commentary, one of the core Confucian classics, there is a passage that asks:

"If you season water with water, who is going to eat it? If you keep playing the same note on your lute, who is going to listen to it? The inadequacy of "agreement" lies in this" (Zhou Commentary, Verse 216).

The proposed framework in this section has both theoretical and practical significance. It presents a detailed theoretical framework for private universities as learning institutions. University leaders should not lose focus on the four elements discussed in Fig. 5 that determine the universities sustainability.

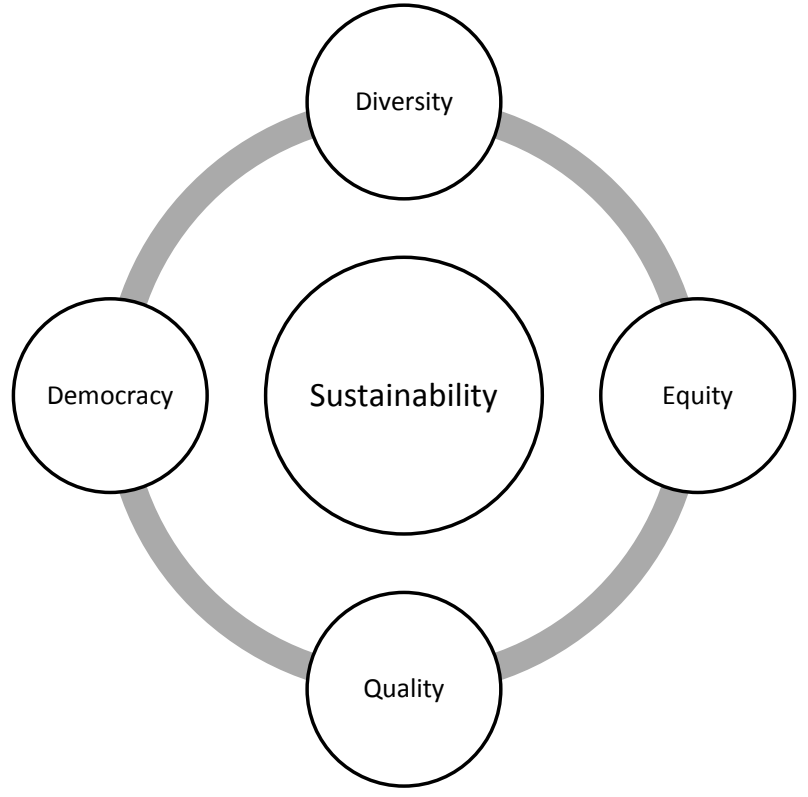

Figure 5. Key Elements of Sustainability

\section{Evaluating the Teaching Effectiveness}

$\mathrm{Yu}$ (2016) explored the differences in the feedback scores of lecturers evaluated by the diploma and degree students in a Malaysia private university. Currently, all students evaluate lecturers teaching at both the diploma and degree levels using the same set of questionnaires. As the entry requirements for the two classes of students are different, the feedback results do not fully reflect the teaching efficiency of the lecturers. An upward reweighting of the feedback scores of Diploma level lecturers to ensure more parity in the teacher evaluation 
process was proposed. University's human resource policies need to be fine-tuned to take into consideration the differences between the two classes of students. The current system of not revealing the various component scores of the feedback process to the lecturers is counter-productive as lecturers do not know which aspects of their teaching need to be improved and which aspects are appreciated by students. For the feedback process to be effective, lecturers need to receive timely and substantive information about their performance.

The main goal of the research was to highlight the differences in the response rate between diploma and degree level students. The research study was conducted on students of the Faculty of Business over a two-semester period. The sample included 30 lecturers who are teaching at both diploma and degree levels. A total of 30 different diploma and 30 degree subjects per semester were chosen. There were 1,100 student participants in the survey. The class size per level ranges from 10 to 80 students per class. The research was based on one online survey exercise per semester in the form of a questionnaire administered by the Registry department.

Universities need to re-compute the overall feedback score of Diploma level lecturers through an upward reweighting of the overall score. From the results of our analysis, the mean differences range from $1.8 \%$ to $5.9 \%$ taking into consideration the standard deviations of both means. Conservatively, we would recommend a $3 \%$ reweighting upwards in the feedback scores of lectures teaching Diploma level subjects to make them more comparable to those teaching Degree level courses. The Adjusted Feedback Scores (AFS) is represented by the equation below:

Adjusted Feedback Scores (AFS) of Diploma level lecturers $=1.03 \mathrm{x}$ initial feedback score.

The multiplier of 1.03 takes into account the different academic standings of the two classes of students and ensures more parity in the teacher evaluation processes between Diploma and Degree level lecturers.

The ongoing process of improving professional teaching is essential for ensuring student learning success and this has to be the main focus of the evaluation process. Our proposed framework recommends that the university incorporates the following elements in a new lecturer appraisal and feedback system. These include:

a) Student Performance;

b) Student assessment of lecturers;

c) Peer observation of classroom teaching;

d) Peer collaboration;

e) Self-assessment, reflection and planning;

f) Introducing Critical Thinking as a compulsory subject at Diploma level;

g) The feedback exercise to be held in the second half of the semester.

The purpose of lecturer evaluation needs to be conveyed clearly to students. Both lecturers and students need to know what aspects of lecturer evaluation are monitored. At the same time, the outcomes objectives, performance indicators and reference standards should be made known by the human resource department to the lecturers. Specific goals are more meaningful than general ones as they help to focus on students' achievements and feedback. They also assist to reduce the gap between actual and desired levels of performance (Yu, 2016).

Lecturers' professional profiles, including specialized knowledge and skills, should be listed clearly and measured against reference standards which are made known to lecturers. The accountability function of lecturer evaluation holds lecturers accountable for their performance. The outcome of a good feedback should result in some form of recognition and reward for it to be effective. Conversely, a poor feedback may result in some kind of sanctions against the lecturer. This policy has to be transparent to lecturers to avoid any feeling of demotivation or disgruntlement. University leaders have the ability to motivate teachers and must create an environment that promotes change (Yu, 2009). They should encourage the use of the feedback process as a legitimate tool for lecturer development and avoid any unnecessary bureaucratic procedures associated with the reward mechanism.

The influence of Confucianism has often lead to a particular learning style on the part of students. Knowledge is regarded as something transmitted by teachers rather than actively discovered by learners, although Confucius often stressed on thinking.

In the Analects, Book 2, Confucius said, "He who learns but does not think is lost. He who thinks but does not learn is in great danger". 
Students in Confucian-influenced societies are generally considered more passive than their Western counterparts. This is demonstrated in classroom participation as many students are reluctant to express their views in class as this might be perceived as expressing public disagreement. University leaders thus have to understand that assessing the teaching capabilities of teachers is only one part of the equation. Equally important is the learning capability of students. Teachers need to be given the opportunity to be exposed to a variety of teaching styles and be trained in delivering classroom instructions which take multiple learning styles into consideration.

In the Analects, Book 2, Confucius said, "A person who reviews the familiar and gets to know what is new, is worthy of being considered a teacher".

\section{Remodeling the University}

This section uses the metaphor of University Remodeling as a framework for analyzing students' choice of a private university and repositioning the university through the rebranding of its professors. Remodeling the university involves reconstructing competencies and strengths of the institution. These elements are critical to the growth of the university. Managing growth requires the understanding of the factors influencing students' choice of a university, institutional commitment towards improving these factors, and rebranding the university to differentiate itself from its competitors. The creation of a strong university brand is a strategic issue that requires close collaboration between university administrators and academicians, and should not be left alone to the marketing department (Yu, 2016).

The study was carried out on a new batch of students enrolling in a private Malaysia university in the second semester of 2016. The sample size consisted of 202 students enrolling in various diploma and degree programs. A self-administered questionnaire was used to collect data from the students. Students were asked to identify and determine the important factors influencing them to choose the university as their choice institution. The questionnaire constitutes 16 factors (program offerings, desired choice, housing, facilities, attraction, teachers profile, reputation, attention received, students' numbers) with response scale ranging from Highly important 1 to Unimportant 5. The second section of the questionnaire consists of 8 factors (student's choice, parents' choice, self-desire, fees, friends, entry requirements, advertisement and social media) with responses ranging from Strongly Agree 1 to Strongly Disagree 5.

Universities need to remodel themselves in the changing marketplace to maintain connectivity with its various stakeholders: students, staff, faculty, and community. The expectation that universities education should be aligned with the market needs implies that universities should promote the career opportunities of their program offerings to their students. Students often consider their prospects of securing employment upon graduation as a proxy for the reputation of their universities (Yu, 2016).

In line with the changing job market, universities have to introduce new programs which are relevant to the industries. These new programs should focus on developing new skill sets or new knowledge of students in preparation for careers in the changing marketplace. This study reveals that there are twenty-four important factors which influence students' choice of a private university. These factors include programmes offerings and facilities, the composition of students and faculty reputation, and promotional activities and affordability. All of these factors comprise a university brand promise. Students are now better informed and are aware of the many alternative universities that they can apply to. The university should take a broader view of branding and not just limit itself to the usual activities of student recruitment, faculty engagement and student experience. It should revamp its brand image to meet the needs of the changing marketplace and to improve the engagement level with both student and staff to enhance their experiences. Universities need to adopt multidimensional enhancements to meet the global benchmarks in order to compete in a globalized world (Mok and Chan, 2008). A study by Gray et al. (2003) on the influence of cross-cultural values on the positioning of international education brand identified learning environment, reputation, graduate career prospects and cultural integration as factors enhancing brand positioning. Ali-Choudhury et al., (2009) noted that a university's brand is a manifestation of the institution's features that distinguish it from others, engender trust in its ability to deliver a certain and level of education.

One key strategy for the university to differentiate itself is to rebrand its professors. Professors play key roles in delivering the university's brand promise. Distinguished professors could easily become their own brands and become ambassadors of the university. Professors can build the brand as an expert in a particular domain and this, in turn, can transcend the boundaries of their personal branding to institutional-wide branding. The university should explore and adopt the concept of emotional branding in the changing education landscape. 
Emotional branding provides the means and methodology for connecting the university products to consumers in an emotionally profound way. It focuses on the desire to transcend personal satisfaction and experience emotional fulfillment. If carried out successfully, emotional branding encourages connectivity and intimacy with the university. This emotional aspect will be the key differentiator between the university and its competitors.

One strategy which the university could adopt is to rebrand professors. For the rebranding process to be successful, there is a need to have a supportive internal organizational culture to groom and develop talented faculty members. Through this talent identification process, professors who receive support through research funding will be able to promote their personal brand names. With brand recognition through the rebranding of professors, universities can move ahead to reinforce its brand and regain customers' confidence. In a hadith narrated by Muslim (No. 17), Abu Yaala Shaddad bin Aws stated that the Prophet (pbuh) said:

"Verily Allah has prescribed proficiency in all things. Thus, if you kill, kill well: if you slaughter, slaughter well. Let each of you sharpen his blade and let him spare suffering to the animal he slaughters".

Zaid and Tamkin (2013) cited that in a hadith narrated by Baihaqi, the Prophet (pbuh) gave special emphasis to itqan (diligence and perseverance) when executing tasks.

"Verily, Allah loves those of you, who, when doing something, do so with itqan".

The place of Confucianism and Islam in the university environment could be enhanced as it shapes the personal lives and wellbeing of many on campus. They are intertwined with a range of issues and themes in society including inter-faith relationships, politics and life choices. As such, leaders need to promote intellectual discussions on the goodness of philosophies and religion to develop a broader understanding of the multiculturalism elements in the institutions. Leaders themselves have to change their mindsets to see goodness and opportunities when faced with challenging situations.

"Verily, along with every hardship is relief"(Al Quran, 94: 5-6).

\section{Reinventing the Leadership}

This section examines leadership qualities among private school principals in Singapore. Findings from the study indicate that effective principals are those who are able to establish trust, create structures that promote principal-teachers' communication and maintain a high level of moral values. Specifically, it presents the findings from the case of ten private commercial schools in Singapore. The study presented an overview of emergent themes and questions related to the roles of the principals and the relations between school and the community. The results from the study indicate that financial goals rank top above all other goals set by the school principals. The emphasis on maximizing financial gain is a cause of concern as many school principals have lost their intellectual integrity as well as their academic values in their pursuit of financial gains.

Effective principals are community builders. They are able to nurture the development of open systems in which parents and members of the community are able to voice their opinions. The challenge for most principals is to foster a community of learning among professional staff They are central agents of change in the system for improving school performance. An effective principal is a necessary precondition for an effective school. The principal's leadership sets the tone of the school, the climate of teaching, the level of professionalism and the morale of the teachers and students. The principals' influence in both the supervisory and instructional domains is strongly related to that of teachers' active participation in decision making, suggesting the benefits of mutuality in school leadership. As community builders, principals must encourage others to be leaders in their own right. Warrick (2017) noted that leaders need to be skilled at building teams, at effectively managing change and creating opportunities to continuously improve and prepare for future success.

The most common goal for all the schools is a financial success - a particular profit or return on investment. Other goals may include improving the educational curriculum, providing a conducive environment and developing good teachers and students relationships. To achieve these goals, the principal must set up a number of sub-goals compatible with its primary goals. These tend to be more specific and usually more immediate in nature. For example, to achieve more student enrollment, schools may offer discounts on school fees or other incentives such as personal computers or tablets. The schools' principals should focus on improvement strategies which are sustainable in the long term. Price competition is a short-term approach and can be detrimental over a longer period (Yu, 2016). 
Principals should be more fully involved in the reforms of the school policies so as to ensure greater adaptability in school management. They need to have the ability to plan and develop a curriculum that enhances teaching and learning for all students. The ability to use educational research, evaluation and planning process to improve student performance is something all principals need to focus on. They also need to possess a high level of moral leadership. This study suggests that very often, moral leadership has been compromised for financial gains. Moral leadership acknowledges that values and value judgments are the central elements in the selection, extension and day-to-day realization of educational purpose. Principals need to possess a portfolio of beliefs and values in issues such as justice, equity, community and schools that function for the main purpose of education. They need to engage participants in the organization and the community in reinterpreting and placing new priorities on guiding values for education. Leadership as moral stewardship means seeing the moral implications of the many daily decisions made by each school administrator (Beck \& Murphy, 1994).

In Islam, there are two types of leadership: official and personal. As a head of state, the Prophet (pbuh) has placed people into official political and religious positions. Leadership is a trust that Allah holds people accountable for:

\section{"You will covet leadership, but it will be a source of regret on the day of rising".}

(Riyad al-salihin, Hadith 677).

Principals need to develop a professional learning community to ensure the sustainability of the school. To be able to achieve this goal, they need to build a school culture and vision that is universally shared by teachers, staff, students and the community. They need to build ethical schools while meeting the moral imperative to provide real learning opportunities to students. Principals who become too focused on managing the day-today activities can unwittingly neglect the important role they can play in helping to create a shared vision for change. Managerial ethical leadership has a significant positive relationship with employees' job satisfaction (Chin, 2013), family and life satisfaction (Zhang and Tu, 2016), sense of occupational well-being (Li et al., 2014), and trust in the organization (Xu et al., 2014).

The Western concept of leadership involves a dichotomy between spirituality and religion. However, in Islam, spirituality and religion are interwoven and interconnected. Islam promotes ijma (consensus) in decision making, and its application could be useful in building a shared vision and mission for the school environment.

\section{Strengthening the Corporate Governance}

Yu (2016) examined the prevalence of private commercial schools which offer overseas franchise degree and diploma programs in Singapore, many of which may not have met the regulatory requirements if strict monitoring actions were to be applied to them. The majority of private commercial schools in Singapore are small and have no proper facilities including libraries, student recreation facilities and computer labs. While over 600 schools have been deregistered since 2009, either voluntarily or involuntarily, following the introduction of the Council for Private Education Act which in 2009, over 290 schools are still in operation. Of these 290 schools, only less than one-fifth can be considered to have proper facilities. This paper explores the possible reasons why some schools are still in operation despite not meeting the recommended regulatory guidelines. It suggests stricter actions could be taken by the Committee for Private Education to ensure that these schools contribute to the improvement of the overall education landscape in Singapore and makes recommendations where the Committee could increase its vigilance on these schools. It also recommends a framework relating to the monitoring and review of the current audit process of private commercial schools. The second part of the paper explores the failure of schools to deliver quality education to their students and the reasons students are still choosing the private education route as an option for their studies. Contrary to popular assumptions, private commercial schools in Singapore pose no significant competition to public schools. Teachers at private commercial schools had not received as much training and development as those in public schools. Profit seemed to be the main driver for these commercial schools.

From the analysis of the questionnaire to students, the researcher found that some of the reasons students choose these schools include the low entry requirements, the lax attendance policy, the low discipline control and the possibility of pressuring the principal for higher examination marks. This is particularly worrying as such a school environment will have negative implications for both students and teachers. Students who have not met the entry requirements may not have a similar level of knowledge as his other classmates. This may slow down the learning process of the whole class. In addition, teachers will be demotivated to teach those students who should not have been admitted into a program in the first place. Principals must become more 
sensitive and aware of their teachers' needs. They have to learn the skills to motivate teachers and to keep teachers' enthusiasms and interests high. Motivated teachers are school assets. The more motivated the teachers, the greater is their work commitment. Providing a good working environment and giving teachers more resources are not quite enough as teachers strive towards a higher stage of personal development.

Failure to implement a stringent attendance policy will only encourage "ghost" students to enroll in private commercial schools. Many of these students are working illegally without the approval of the Immigration Department or the Ministry of Manpower. Schools tried to circumvent the $90 \%$ attendance policy set by the Immigration Department by declaring false attendance records to the authorities. Students working illegally are a cause of social problems and many of these schools are contributing to this problem as profit-making is their main objective.

Principals of private commercial schools are more likely to give in to the pressure on students to increase their exam grades. They may make the decision alone without consultation of the other Examination Board members. As most principals of these schools are also members of the Academic and Examination Boards, there is normally no higher management level person to oversee his actions.

Feedback from students showed that they were generally quite indifferent about the quality of education received from their schools. This may be due to their lower expectations in terms of quality education and facilities. They felt that while the teachers have the qualifications to teach them in class, they are less concerned about the learning outcomes of students. This may be due to a number of demotivating factors of teachers which include the quality of students in a class, the attendance of the students, the lack of interactions with students, the salary of the teachers, and the relationship with the principals.

Most teachers at these schools were not satisfied with their job. The reasons include the perception that they are being paid lower than the peers at public universities. They felt little recognition for their contribution and that the quality of students and their poor attendance were some of the major issues that have not been addressed by the principals.

The analysis of teachers' survey showed that they were concerned about the entry requirements of students. Teachers felt that the schools have not adhered to the entry requirements and have accepted students without the proper qualifications. Students who do not meet the entry requirements are more likely to perform poorly in school and this demotivates teachers. While profit motive may undermine the schools' strict adherence to entry requirements, principals have often compromised the professionalism of teachers by admitting unqualified students. This may include students who have not attained the proper English language proficiency or who have not meet the basic academic qualifications for entry into a program.

Training and development is another area which has not received high priority as principals are not willing to invest in upgrading the skills of lecturers and staff for fear that they may leave after gaining the additional skills and knowledge. Training and development promote significant and worthwhile change in teachers' practice and principals need to be supportive of this if they are determined to bring about improvement in the school. Teachers need to develop not only the factual knowledge but also the procedural knowledge of when, how and under what conditions to apply their new skills.

The researcher proposed a new compliance audit framework for regulators to improve the prevailing audit process of private commercial schools which offer self-developed and franchise programs. This new audit framework addresses the current shortcomings of the current audit process. The shortcomings had given the opportunity for schools' operators to circumvent the existing regulatory requirements. The areas, which require special focus, include the following:

1) Enrolment Verification;

2) Attendance;

3) Entry Requirements;

4) Training \& Learning;

5) Program Approval;

6) Registration of faculty (Full Time and Part Time);

7) Compliance with Accounting Policies.

A robust compliance program is essential to ensure that these schools comply with their obligations under the relevant legislation and that instances of non-compliances are addressed by enforcement or other actions. Achieving audit quality requires careful audit and quality control procedures. Such a disciplined and structured 
approach would encompass careful planning of the audit process as well as impromptu and unannounced visits to these schools. It is imperative that when auditors and inspectors perform the audit, they understand the particular school's environment at normal times and not just during the audit period where much insincere efforts will be put in by the school administrators to project an image of efficiency and compliance.

The new audit framework in Figure 7 took into account the four elements of education institutions (Dimmock, 2007). The first element of Organisational Structure involves how human and physical resources are established and deployed. The second element of Leadership, Management and Decision-Making Processes, deals with leadership styles and performance appraisals. The third element of Curriculum looks at the objectives, breadth and depth, and relevance of the curriculum offered. The last element of Teaching and Learning examines the delivery of courses, teacher-student relationship and learning outcomes.

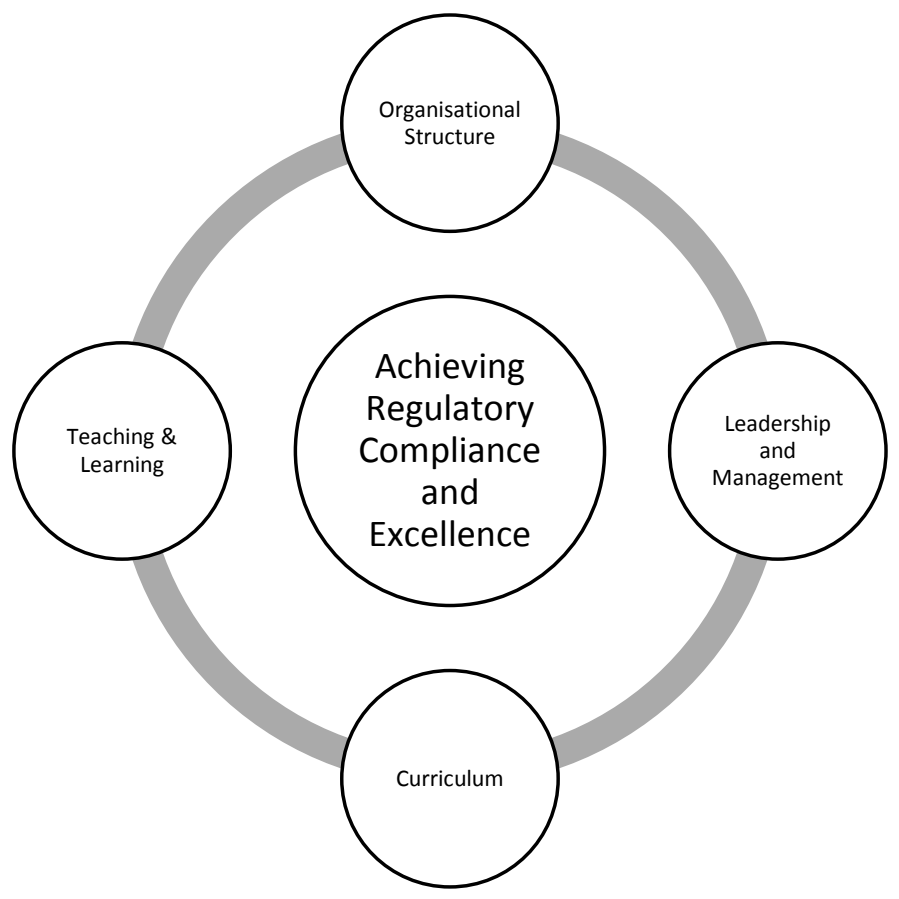

Figure 7. Improved Audit Framework

Adopting the conceptual audit framework in Figure 7 is relevant to understanding the underlying mechanism of complex university governance dynamics. There are multiple issues, which involve multiple stakeholders which could be viewed from five major dimensions:

a) Government regulations - this may include the level of self-autonomy granted to some universities.

b) Organization culture - where universities follow the practices of enterprises and emphasize market competition and sustainability.

c) Academic governance - where faculty members retain authority and decision-making power in issues such as administration, teaching and academic standards.

d) Bureaucracy - where the university retains a well-defined hierarchy of authority and establishes clear reporting relationships. The effectiveness of leaders centers on their leadership capabilities and vision for their institution.

e) Competition - which includes international benchmarking of universities to create world-class universities.

Governance is defined as the manner in which power or authority is exercised in the allocation and management of resources. Clark (1983) noted that higher education governance arrangements in some systems are more influenced by the state, others by market forces and some by group academics.

China has traditionally adopted a supervision-oriented model where universities are regulated by the central government (Huang, 2006). Policies and laws that enable and facilitate autonomy are largely absent in public universities. Government bureaucracies dictate the rules of the universities, including curriculum design and the regulation for teacher certifications.

Private universities have different sets of governance issues as their Presidents are nominated by the owners or funders of the institutions. They should be better regulated to ensure that their performance is consistent 
with accepted standards and that their students receive the quality of education as promised. Their leaders should be accountable to the beneficiaries and stakeholders.

For universities in Malaysia, Muslim donor agencies, as well as individuals, should give Zakat (obligatory giving) without expecting anything in return. Hashim (2012) noted that many Muslim private higher education institutions seem to suffer from poor leadership, which lack integrity in dealing with money. The leadership lacks vision, ideas, analytical as well as social skills.

Good governance in Islam is described by the term al-siyasah al shariyyah, which defines how power can govern the needs and welfare of the public. The basic cooperation between the ruler, administrator and the citizen is inseparable. Applying this to the university environment, the cooperation between the leader, staff, students and other stakeholders is essential to attain al-falah (felicity). The Islamic philosophy of education aspires to shape human being based on three dimensions: sense, mind and religious faith (with include ethics). According to Islam, every individual will be responsible for his good or bad deeds and accordingly he will be rewarded or punished. Allah says:

"..whosoever does good equal to the weight of an atom shall see it. And whosoever does evil equal to the weight of an atom shall see it" (Surah Az-Zilzal. Verse 7-8).

Increasing competition for academic talent has driven many universities to allow more autonomy and freedom to academic personnel. Chan and Yang (2017) noted that the faculty prefers a bureaucratic environment controlled by collegiality where procedures are formulated by academics rather than non-academic personnel.

Global competition has prompted some Malaysian universities to change their academic culture from collegial to bureaucratic and corporate. The internationalization of universities requires a transformation process of university governance in a global context. In China, higher education institutions are experiencing a changing governance culture of combining administrative bureaucracy with auditing process to align higher education with national interests. Quality assurance of Chinese universities consist of both external and internal quality assurances, and is led by two government agencies: a) the Academic Degree and Graduate Education Development Centre which is responsible for the assessment of graduate education, and b) Higher Education Evaluation Centre which is responsible for undergraduate education. In addition, universities have the own quality assurances department for internal evaluation.

Confucianism has much to offer in enhancing university leaders' conduct and governance standards. It can be integrated formally into the university governance system with the implementation of strict ethical standards, education, fear of punishment by society and peer pressure. The concept of junzi associates well with the concept of good governance.

"When right principles prevail in the kingdom, government will not be in the hands of the great officers" (Analects, 4.16).

There is no one ideal governance style, which could be applicable to all universities. The ideal governance style depends on a number of factors such as the history of the institution, the national and international forces and the interactions between academics and university leaders.

\section{Summary and Conclusion}

Excellence in higher education is not easily defined as it has many dimensions, which are unique to specific cultural contexts. It is highly infused in the culture of the nations and values of its people. China, Singapore and Malaysia are perceived to be having high context cultures, which emphasize paternalism, collectivism, social relations, harmony, trust and education. Confucianism and Islam have a great influence on the leadership style of managers in these countries. Confucian teachings are characterized by the emphasis on virtuous conduct through education, promoting harmony and respecting hierarchy. Education is seen as a means to selfimprovement, management of one's family and governing the state, with the goal to promote justice and virtue to the world. Its perspective on shared values and moral development constitute the foundation for propagating excellence in many higher education institutions today.

The Islamic perspective on the role of education focuses on knowledge, wisdom and action. Education is related to the acquisition of knowledge and transformation of one's personality. Knowledge comes from Allah and all actions should be carried out for Allah's glory. In the 2015 - 2025 Malaysian Education Blueprint, the Malaysian government had emphasized the need to develop students to possess both knowledge and skills as 
well as ethics and morality. To achieve this goal for their institutions, leaders themselves need to be morally upright, spiritually grounded, compassionate and caring.

This paper has adopted an indigenous Confucian and Islamic perspective based on self-cultivation and moral perfection, respectively. This perspective has proved to be helpful for developing a humanistic theoretical model that integrates three important components for achieving educational excellence: leading self, leading others and leading the institution. The model analyses the dominant values and the processes underlying the influence of these values in various domains of universities leaders' behaviors (Table 1).

The researcher began by examining the influence of Confucianism and Islam on educational leadership. The Confucian tradition emphasizes human relationships and right education as central to harmony and order. Islam's ideology of humanism calls for a human to strive for moral perfection through religion. Moral perfection is possible if humans follow $l i$ (Confucian rituals) or abad (Islamic rules of conduct). Subsequent sections highlighted this study's contribution to further understanding of educational leadership concepts and practices in China, Singapore and Malaysia. The findings from this study can be employed by higher education leaders as a guideline in their endeavor to lead their institutions. Based on the recommendations of the author, it may thus help to look at higher education leadership from a different angle, that of development of personal virtues which seems to a key factor on developing institutional excellence.

Table 1. Humanistic Approach to Leading Higher Education Institutions

\begin{tabular}{|c|c|c|}
\hline & Confucian Values & Islam Values \\
\hline \multirow[t]{8}{*}{ Leading Others } & Humility & Sincerity \\
\hline & Group Orientation & Good Intention \\
\hline & Reciprocity & Openness \\
\hline & Harmony & Brotherhood \\
\hline & Sincerity & Cooperation \\
\hline & Benevolence & Thankfulness \\
\hline & Trust & Patience \\
\hline & Relationship & Trust \\
\hline \multirow[t]{9}{*}{ Leading Self } & Face Saving & Knowledgeable \\
\hline & Humility & Optimistic \\
\hline & Obedience & Value of Time \\
\hline & Hard work & Integrity \\
\hline & Graciousness & Perseverance \\
\hline & Tradition & Diligence \\
\hline & Wisdom & \\
\hline & Integrity & \\
\hline & Righteousness & \\
\hline \multirow[t]{11}{*}{ Leading the Institution } & Group Orientation & Knowledgeable \\
\hline & Hierarchy & Responsible \\
\hline & Respect for authority & Openness \\
\hline & Responsible & Justice \\
\hline & Harmony & Cooperation \\
\hline & Ethical & Consistent \\
\hline & & Accountable \\
\hline & & Compliance \\
\hline & & Innovativeness \\
\hline & & Infrastructure \\
\hline & & Ethical \\
\hline
\end{tabular}

\section{References}

1. Ali-Choudhury, R., Bennett, R., \& Savani, S. (2009). University marketing directors' view on the components of a university brand. International Review on Public and Nonprofit Marketing, 6(1), 11-33.

2. Bandura, A. (1997). Self-efficacy: The exercise of control. New York: W. H. Freeman.

3. Barsh, J.C., Capozzi, M.M. \& Davidson, J. (2008). Leadership and innovation. The McKinsey Quarterly, No.1, New York.

4. Beck, L.G., and Murphy, J. (1994). Ethics in education leadership prograns: An expanding role. Thousand Oaks, CA: Corwin Press.

5. Bizumic, B., Smithson, M., \& Van Rooy, D. (2010). Reconceptualized ethnocentrism and its consequences. Paper presented at the Thirty-Third Annual Scientific Meeting of the International Society of Political Psychology in San Francisco, CA, USA. 
6. Carver, F. D., \& Sergiovanni, T. J. (1971). Complexity, adaptability, and job satisfaction in high schools: An axiomatic theory applied. Journal of Educational Administration, 9(1), 10-31.

7. Chan, S.J. and Yang, C.Y. (2017). Governance styles in Taiwanese universities: Features and Effects. International Journal of Education Development, https://doi.org/10.1016/j.ijedudev.2017.10.007.

8. Chin, T. (2013). How ethical leadership encourages employee voice behavior in china: The mediating role of organizational harmony. International Business Research, 6(10), 15-24. doi:10.5539/ibr.v6n10p15.

9. Clark, B.R. (1983). The Higher Education System: Academic Organization in Cross National Perspective. University of California Press, Berkeley.

10.Crotty, M. (1998). The foundations of social research: Meaning and perspective in the research process. Thousand Oaks, CA: Sage.

11.Frances, R., \& Lebras, C. (1982). The prediction of job satisfaction. International Review of Applied Psychology, 31, 391-410.

12.Frankel, J.R., \& Wallen, N.E. (2003). How to design and evaluate research in education. Boston, MA. McGraw-Hill.

13.Fu, J. (2013). Comparative Study on Presidents' Tenure between National University of Modern China and Private University, Meitan Higher Education, 31(1), 47-50.

14.Goleman, D. (1998). Working with emotional intelligence. New York: Batam Books.

15.Guo, J., and Xiong, S. (2010). An empirical study of research performance evaluation for Chinese universities of 31 areas. Journal of Intelligence, 29(9), 83-88.

16.Gray, B.J., Fam, K.S. \& Lalnes, V.A. (2003). Branding universities in Asian markets. Journal of Product \& Brand Management, 12(2), 108-120.

17. Grix, J. (2002). Introducing Students to the Generic Terminology of Social Research. Politics, 22(3), 175-186.

18.Hall, Edward, T. (1976). Beyond Culture. NY: Anchor Books.

19.Halstead, J.M. (2004).An Islamic Concept of Education. Comparative Education, 40(4), 517-529.

20.Hashim, R (2012). Muslim private higher educational institutions in Malaysia: issues and challenges. Islam and Civilisational Renewal, 3(3), 474-488.

21.Huang, F. (2006), Incorporation and University Governance: A Comparative Perspective from China and Japan, Higher Education Management and Policy, 18(2). Available at: https://doi.org/10.1787/hemp-v18art10-en.

22.Li, Y., Xu, J., Tu, Y., \& Lu, X. (2014). Ethical leadership and subordinates' occupational well-being: A multi-level examination in China. Social Indicators Research, 116(3), 823-842. doi:10.1007/s11205-013$0321-\mathrm{z}$.

23.Lu, Y. (2016). Academic Leadership: A logical starting point for reconstructing the modern university governance system. Higher Education Exploration, 6, 34-38.

24.Lu, C. S., \& Lin, C. C. (2014). The effect of ethical leadership and ethical climate on employee ethical behavior in the international port context, Journal of Business Ethics, 124, 209-223.

25.Maslow, A. H. (1954). Motivation and personality. New York: Harper \& Brothers.

26.Merriam, S.B. (1998). Qualitative research and case study applications in education. San Francisco, CA: Josey-Bass.

27.Mohr, J.S. (2010). Marketing of high-technology products and innovations (3rd ed). Upper Saddle River, New Jersey, US: Pearson.

28.Mok, K.H. and Chan, Y. (2008). International Benchmarking with the best universities: Policy and practice in mainland China and Taiwan. Higher Education Policy, 21, 469-486.

29.O'Neil, J. (1996). On emotional intelligence: A conversation with Daniel Goleman. Educational Leadership, 54(1), 6-11.

30.Ogawa, R.., \& Bossert, S. (1995). Leadership as an organizational quality. Educational Administration Quarterly, 31, 224-243.

31.Perkins, D. (1995). Outsmarting I.Q: The emerging science of learnable intelligence. New York: The Free Press.

32.Pring, R. (2000). Philosophy of Education Research. London: Continuum.

33.Rowe, K.J., \& Rowe, K.S. (1999). Investigating the relationship between students' attentive-inattentive behaviors in the classroom and their literacy progress. International Journal of Educational Research, 31, $1-138$.

34.Ryan, R. M., \& Deci, E. L. (2017). Self-determination theory: Basic psychological needs in motivation, development, and wellness. New York: Guilford Publishing.

35.Ryan, J. \& Louie, K. (2007). False dichotomy?: 'Western' and 'Eastern' concepts of scholarship and learning. Educational Philosophy and Theory, 39(4), 404-417. 
36.Salopek, J.J. (1998). Train your brain. Training and Development, 52(10), 26-33.

37.Sashkin, M., \& Walberg, H. J. (1993). Educational leadership and school culture. Berkeley, CA: McCutchan Publishing Corporation.

38.Silverman, D. (2000). Doing qualitative research: A practical handbook. London: Sage.

39.Sun, Q. (2008). Confucian educational philosophy and its implication for lifelong learning and lifelong education. International Journal of Lifelong Education, 27(5), 559-578. doi:10.1080/01411920802343269.

40.Sweeney, J. (1981). Teacher dissatisfaction on the rise: Higher-level needs unfulfilled. Education, 102, 203-207.

41.Tan, C. and Ibrahim, A. (2017). Humanism, Islamic Education and Confucian Education, Religious Education, 112(4), 394-406.

42.Trusty, F. M., \& Sergiovanni, T. J. (1966). Perceived need deficiencies of teachers and administrators: A proposal for restructuring teacher roles. Educational Administration Quarterly, 2, 168-180.

43.Warrick, D. (2017). The urgent need to educate present and future leaders in organizational development and change. Organizational Development Practitioner, 49(3), 52-58.

44.Xu, K. and Wang, G. (2018). Confucianism: The question of its religiousness and its role in constructing chinese secular ideology. Journal for the Study of Religions and Ideologies, 17(50), 79-95.

45.Yu, S.O. (2016). Reexamining Education Research Methodologies - Collaborative rather than Competitive. Bulgarian Journal of Science and Education Policy, 10(1), 124-141.

46.Yu, S.O. (2016). Need for Regulatory Revamp of Private Institutions. Perspectives of Innovation, Economics \& Business, 16(1), 55-78.

47.Yu, S.O. (2016). Using students' feedback to evaluate teachers' effectiveness. Journal for Educators, Teachers and Trainers, 7(1), 182-192.

48.Yu, S.O. (2016). Reculturing: The key to sustainability of private universities. International Journal of Teaching and Education, 4(4), 88-105. doi:10.20472/TE.2016.4.4.005.

49.Yu, S.O. (2016). Remodeling the University as an Institution of Choice. International Journal of Development Research, 6(5), 7846-7852.

50.Yu, S.O. (2012). Complexities of multiple paradigms in higher education leadership today. Journal of Global Management, 4(1), 92-100.

51.Zaid, M. and Tamkin, B. (2013). Muslim Consumer Behavior: Emphasis on Ethics from Islamic Perspective. Middle-East Journal of Scientific Research, 18(9), 1301-1307.

52.Zhang, S., \& Tu, Y. (2016). Cross-domain effects of ethical leadership on employee family and life satisfaction: The moderating role of family-supportive supervisor behaviors. Journal of Business Ethics, 1-13. doi:10.1007/s10551-016-3306-4. 